\title{
DETERMINING THE PROVENANCE OF CAYO POTTERY FROM GRENADA, LESSER ANTILLES, USING PORTABLE X-RAY FLUORESCENCE SPECTROMETRY*
}

\author{
R. B. SCOTT,${ }^{1,2} \dagger$ (D) B. NEYT,${ }^{1}$ C. HOFMAN ${ }^{2}$ and P. DEGRYSE ${ }^{1,2}$ \\ ${ }^{1}$ Centre for Archaeological Sciences, Geology Division, Department of Earth and Environmental Sciences, \\ Katholieke Universiteit Leuven, Celestijnenlaan 200E, BE-3001 Leuven, Belgium \\ ${ }^{2}$ Faculty of Archaeology, Leiden University, Reuvensplaats 4, Leiden 2313KX, The Netherlands
}

\begin{abstract}
Portable XRF was used to analyse the chemical composition of 52 indigenous Cayo ceramics from excavations and from private collections on Grenada, Lesser Antilles. Initially, a comparative baseline of data representing three different islands (Grenada, St Vincent and Trinidad) was created by analysing with $\mathrm{XXRF}$ ceramic material that had previously been analysed both chemically and petrographically. The field data, when compared to the laboratory baseline data, indicated that the majority of the ceramics were made with clay local to Grenada. Four samples were potentially made with clay from another, as yet unidentified, source.
\end{abstract}

KEYWORDS: PXRF, CAYO POTTERY, LESSER ANTILLES, PETROGRAPHY, KORIABO

\section{INTRODUCTION}

Ceramics have been a major focus for archaeometric and archaeological studies since the 1950s, in part due to their virtually indestructible nature, which makes them apparent in large quantities at many archaeological sites (Tite 2008). Stylistic and typological analyses are often used to help provide a chronology for a site, while chemical and petrographic analyses can help to determine the provenance of the object or the production technologies used (Degryse and Braekmans 2014). A combination of analytical work-that is, typological, chemical and petrographic - can lead to discussions about the distribution of specific wares and/or the extent of influence of a specific workshop. The information derived from provenance studies can also be used in wider archaeological research to help determine trade routes and/or exchange mechanisms. Studies of ceramics found in the Caribbean have been largely based on stylistic analyses (Rouse 1992; Boomert 2011; Bright 2011), with some notable exceptions (e.g., Hofman et al. 2008 for a review; Descantes et al. 2008; Ting et al. 2016). In other words, assumptions are made that specific styles can be related to specific regions, chronologies and/or people. These stylistic studies are usually central to archaeological interpretations of a site, region or period (Tite 2008).

The application of analytical methods to the study of ancient ceramics is a valuable compliment to archaeological investigations, contributing to the reconstruction of the life cycle of the ceramic and the behaviour of the people involved in that life cycle (Tite 2008). Traditionally, provenance studies of ceramics have combined petrographic and destructive chemical analyses of the material (Degryse and Braekmans 2014). However, this approach is not suited to materials held in museum and private collections, which often require a non-destructive analysis of the ceramic object. Objects where destructive sampling is impossible will preclude petrographic

\footnotetext{
*Received 30 September 2016; accepted 3 September 2017

†Corresponding author: email becki.scott@kuleuven.be

(C) 2018 University of Oxford
} 
studies, along with techniques traditionally used to determine the chemical composition, such as INAA or ICP-MS (Speakman et al. 2011; Hunt and Speakman 2015). For chemical analyses, archaeologists are turning more and more to non-destructive techniques such as IR, Raman spectroscopy or PIXE (Wisseman et al. 2004; Gajić-Kvaščev et al. 2012) and to non-destructive, portable techniques such as pXRF (e.g., Mantler and Schreiner 2000; Wisseman et al. 2004; Schreiner et al. 2004; Carter and Shackley 2007; Shackley 2011; Shugar and Mass 2012; Hunt and Speakman 2015; Scott et al. 2016a,b). However, it is important to note that while non-destructive techniques have been used to answer specific questions, a thorough study of provenance will usually require a certain degree of destructive analysis.

Part of the interdisciplinary HERA research project 'Caribbean connections: cultural encounters in a New World setting' concerns the analysis pre-colonial and early colonial ceramics from across the Lesser Antilles. The aim is to determine where ceramics were manufactured, what their typical compositions are and to what extent pottery or the raw materials were being transported between the islands. Eventually, the study aims to determine the extent to which this exchange also occurred between the mainland and the islands in the late pre-colonial and early colonial period. In order to achieve this aim, early colonial Cayo ceramics from private collections in Grenada were analysed in the field with pXRF to determine their chemical composition. Portable $\mathrm{XRF}$ was chosen because the ceramic objects could neither be sampled for destructive analysis nor exported from the island. Although pXRF can provide fast, qualitative data, these will only be comparable to other qualitative data collected using $\mathrm{pXRF}$ with the same analytical parameters (Scott et al. 2016a), on similar types of samples, subjected to the same methods of preparation. Many studies have shown that $\mathrm{pXRF}$ can often produce inaccurate elemental concentrations that pattern in accurate ways (e.g., Craig et al. 2007; Nazaroff et al. 2010; Goodale et al. 2012; Johnson 2014). A reliable provenancing study requires three main factors: (a) adequate regional-scale sampling to determine the range of sources represented; (b) an understanding of the variability of the sources; and (c) an appropriate archaeometric technique and methodology to produce valid reproducible source determinations (Lundblad et al. 2008). For ceramic analysis with $\mathrm{pXRF}$, it is therefore essential to build a geochemical library of appropriate sample material using similar tools (i.e., the same model of pXRF) (Morgenstein and Redmount 2005; Hunt and Speakman 2015), ensuring that the samples themselves have a similar matrix and are prepared in the same way prior to analysis. It is also necessary to create a method of comparing qualitative pXRF field data with quantitative chemical and petrographic data obtained in the laboratory, and to build a suitable pXRF geochemical library. This paper outlines the methodological approach used for the pXRF analysis of ceramics found on Grenada and determines the likelihood of a local provenance.

\section{Background}

Cayo ceramics are associated with the Carib or Kalinago presence in the Lesser Antilles, and have been found throughout the islands between Grenada and Guadeloupe. Cayo pottery probably ranges in date from the late pre-colonial period (post-AD 1200) through to the early colonial period (16th to early 17th centuries) (Boomert 1986, 2011; Hofman and Bright 2010; Hofman and Hoogland 2012; Hofman et al. 2015; Petitjean Roget 2015). Up to now, approximately 20 Cayo sites have been registered in the Windward Islands. The majority of these sites are located on Grenada and St Vincent. Their location is strategic, mainly on the Atlantic side of the islands, where the coast is steep and more difficult to access. The sites are often on top of a ridge, adjacent to a river (Hofman and Hoogland 2012; Hofman et al. 2014). Cayoid ceramics 
reflect a mosaic-like cultural aggregate with mainland Koriabo and Greater Antillean Chicoid affiliations, which evidence the wide-ranging contacts of the Kalinago in early colonial times (Boomert 1986, 2004, 2011; Hofman and Hoogland 2012; Hofman 2013; Hofman et al. 2014; Petitjean Roget 2015). Cayoid ceramics were first described by Earle Kirby and Henri Petitjean Roget in the 1970s, and since the 1980s have been extensively documented by Arie Boomert (Boomert 1986, 2011). In general terms, Cayo pottery is characterized by vessels with a variety of shapes sometimes embellished with decorations, modelled decorations, incisions or painting. Unrestricted bowls with carinated rims, often with white painted internal surfaces and designs in yellow, red or black, are very characteristic. These bowls are very typical of the Koriabo style of the Guianas and can be found as far as northern Brazil (Stephen Rostain pers. comm. 2016). Another characteristic vessel is the large restricted jar made of reddish clay, with very large diameter. These may have served as containers for cassava beer (ouicou) mentioned by the early French 17th-century chroniclers. In some cases, these jars have modelled decorations of human faces. A fair number of flat griddle fragments are associated with the Cayo ceramic assemblages; these have typical scraped bottom surfaces. The fabric and compositional analysis of the Cayo pottery from the Argyle site on St Vincent has shown that the majority of the sampled pottery was manufactured from clays found in the vicinity of the site (Hoogland et al. 2011; Hofman and Hoogland 2012). Cayo ceramics from early colonial-period sites are also often associated with European artefacts.

\section{METHOD}

While pXRF analyses are often a popular choice in situations where destructive analysis is impossible or the sample must be analysed in situ, a simple 'point and shoot' approach will be of little use for generating quantitative data. Although pXRF manufacturers often claim that these instruments can be used to quantify the chemical composition of materials using factory calibrations, these are not usually designed for archaeological or geological material (Goren et al. 2011; Ownby 2012; Johnson 2014; Hunt and Speakman 2015; Scott et al. 2016a,b). Irregular surfaces and heterogeneous matrices often introduce error into the quantified measurements (Forster et al. 2011). Heterogeneous materials such as ceramics usually require homogenizing via a method such as powdering before quantitative analyses can be performed. The Cayo ceramic material is fairly coarse-grained; therefore, enhancement and absorption matrix effects encountered during pXRF analyses are further complicated by variable grain size, heterogeneity and mineralogical effects. While the X-rays can pass through smaller grains and excite deeper within the sample, giving a representation of the bulk material, the X-rays may not fully penetrate larger grains, thereby only exciting a single phase (Hunt and Speakman 2015). Similarly, mineralogical effects arise from differences in the crystal structure, composition and density of the different mineral phases, leading to differential attenuation of the X-rays (Hunt and Speakman 2015). For example, a small silicon grain of $20 \mu \mathrm{m}$ diameter can absorb up to $75 \%$ of the intensity of the Ti-K line radiation (Goren et al. 2011). Chemical effects can also occur where different oxidation states can cause wavelength shifts, although this usually only occurs for the light elements (Krusberski 2006). The powdering of samples will help to reduce any issues caused by varying grain sizes and mineralogy (Helmig et al. 1989; Wheeler 1999; Lundblad et al. 2008; Hunt and Speakman 2015; Scott et al. 2016a,b). Quantification can also be achieved with the use of suitable matrix matched standards, which can help to control the matrix effects that reduce the sensitivity of the instrument. However, matrix matched standards for heterogeneous materials are almost impossible to find. Therefore, while pXRF analyses are capable of analysing an object non- 
destructively, the lack of sample preparation and/or matrix matched standards will introduce error into the quantified data. For these reasons, the $\mathrm{pXRF}$ was used to generate qualitative data, which could be related via a baseline to quantified geochemical and petrographic data. As recommended in the literature (Goren et al. 2011), the baseline was formed by analysing with pXRF fragments of ceramic, from three different islands in the Lesser Antilles, which had previously been analysed both chemically and petrographically.

\section{Pilot study}

Prior to the pXRF fieldwork on Grenada, a series of laboratory analyses were undertaken, in order to determine the optimum operating parameters and to create a compositional baseline for ceramics from the Lesser Antilles. Ninety-eight ceramic fragments from the islands of Trinidad, St Vincent and Grenada were analysed using pXRF. A previous pilot study compared the results of the pXRF signal from the surface and cross-section of 65 ceramic fragments (40 from Grenada; 25 from Trinidad). The aim of the study was to observe how the pXRF signal for light elements is affected when a potentially weathered surface is measured. To this end, the instrument was operated at $20 \mathrm{kV}$ and $55 \mu \mathrm{A}$ for $60 \mathrm{~s}$ per measurement, no vacuum or filter being used. Where possible, a minimum of two measurements were taken on each cross-section or surface and the average values of each were used in the subsequent comparisons.

This indicated that there was some compositional variation between the surface and crosssectional measurements for $\mathrm{Al}, \mathrm{Si}, \mathrm{P}$ and, in particular, Ca (Fig. 1). A number of fragments had noticeable patches of Ca-rich encrustation, which is a common deposit on excavated ceramics (Freestone 2001). However, correlations between Ca and P, which suggest the precipitation of calcium phosphate (Freestone 2001), were only found on the surface measurements.

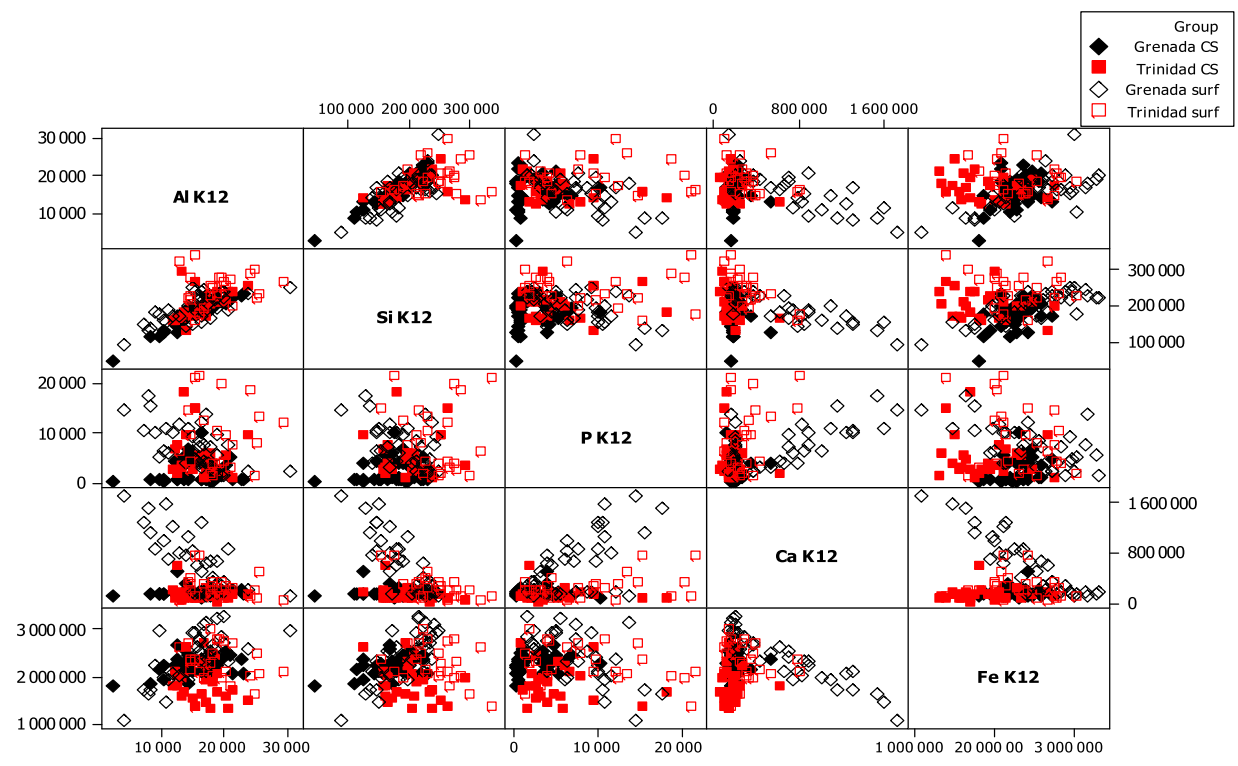

Figure 1 A matrix plot comparing peak area counts for the cross-sections (filled shapes) and surfaces (open shapes) of ceramics from Grenada (black diamonds) and Trinidad (red squares). [Colour figure can be viewed at wileyonlinelibrary. com] 
The Fe signal had a small increase in all cases, but did not correlate with elements such as $\mathrm{Ca}$ or $\mathrm{P}$, indicating that this element is not being precipitated in the ceramics, despite studies of other ceramics noting this phenomenon (Franklin and Vitali 1985; Freestone 2001). Similarly, the overall condition of the fragments did not suggest any obvious physical deterioration such as structural weakening. Therefore, while some obvious precipitation is occurring on the surface of the ceramic, this is only affecting the lighter elements, and these patches could be avoided. Likewise, the overall signal (with the exception of the above-mentioned elements) did not vary noticeably between sites on the same island. This was taken as an indication that any soil debris adhering tp the pores of the ceramic after initial post-excavation cleaning did not have a noticeable effect on the subsequent analyses.

\section{Baseline creation -laboratory analyses}

Although cross-sections of the 98 ceramic fragments were available for evaluation, measurements were conducted on the external surface of the ceramic. This was because, in the field, it would only be possible to analyse the external surface of whole ceramic objects. All samples had been cleaned during post-excavation; however, they were not cleaned further for this study because the researchers would not be permitted to clean the objects in the private collections. All of the 98 ceramics had previously been analysed destructively by either laboratory XRF or ICP-OES (henceforth referred to as the laboratory data), so the chemical composition was known. Of these ceramics, 64 were also analysed petrographically.

A Bruker Tracer III SD was operated at $40 \mathrm{kV}$ and $30 \mu \mathrm{A}$, for $60 \mathrm{~s}$ per analysis, no filter or vacuum being used. This allowed the screening of all the elements present in the sample. Although $40 \mathrm{kV}$ is not ideal for the analysis of light elements in the sample, it gives good results for the mid-range elements that prior quantitative chemical analysis had indicated could be useful for provenancing purposes. Since a previous pilot study had indicated that light elements such as $\mathrm{Al}, \mathrm{Si}, \mathrm{P}$ and $\mathrm{Ca}$ were affected by surface corrosion, it was decided that further targeting of these elements by using a different voltage would not be necessary. Rather than using a selection of filters to reduce the background in different areas of the spectrum, the decision was made to verify the measurability of each elemental peak by using the signal-to-noise ratio (SNR). The SNR is the ratio between the net intensity of the peak and the noise. The noise is calculated as the square root of the background intensity. If an element is present in the sample and detectable above the measured background, then the SNR is $>3$. Where possible, each of the 98 fragments were measured a minimum of two times in different places on the surface: in some cases, more measurements were taken. The spots chosen were either on a flat or convex surface, in order to minimize the air gaps. An irregular surface can cause further attenuation of the X-rays, and ultimately affect the fluorescence intensity of different elements (Potts et al. 1997). However, studies by Forster et al. (2011) have indicated that analyses of a convex ceramic surface result in reasonable accuracy and precision for most element ratios. In addition, patches of obvious encrustation were avoided. However, in some cases, due to the size and shape of the available fragments and the presence of encrustation, only one surface measurement was possible. Data were collected using the Bruker S1PXRF software and were then imported into the Bruker ARTAX software. ARTAX was used to determine the peak area values for each element in the sample. Within the ARTAX programme, the user identifies the elemental peaks present and the software performs a Bayesian deconvolution. The user is then presented with the net peak area intensity and background intensity for each identified element in the spectrum, along with an estimation of the quality of the fit. 


\section{Field analyses}

Fifty-two Cayo ceramic objects from two private collections on the Caribbean island of Grenada were analysed with pXRF, using the same parameters and methodology as those determined in the laboratory. The samples consisted of whole vessels and large sherds from the sites of Telescope Point and La Poterie, on the east coast of the island (Table 1). The two sites date to the early colonial period and finds included Cayo ceramics, European faience earthenware, coins, metal, beads and faunal remains. Of the latter, some had a clear mainland provenance and were worked into flutes and pendants (Hofman 2016). The two collections analysed probably represent the most complete assemblage of Cayo pottery in the islands to date, and include a large variety of vessel shapes and decorative modes. Since the ceramics had been cleaned independently by the owners, no further cleaning of the samples was attempted by the authors. In order to minimize any post-depositional influence on the data, each ceramic object was measured on an area of the external surface without obvious visible alteration. Likewise, in order to compensate for heterogeneity in the sample, as far as possible, each ceramic object was measured two to three times and the average composition of each was determined.

RESULTS

\section{Laboratory analyses}

The petrographic analyses showed two distinct petrographic groups. All of the Grenada samples show abundant plagioclase (often zoned) and amphibole (hornblende/oxyhornblende) as mineral inclusions, while basalt-andesite rock inclusions are common. The inclusions point to a generally mafic volcanic origin for the clay raw material. Most of the St Vincent samples show abundant plagioclase and amphibole (actinolite) inclusions, and rock inclusions that are mostly basaltic to andesitic (a few samples contain minor amounts of more quartz-rich inclusions). The inclusions point to a generally mafic volcanic origin for the clay raw material. Quartz fragments, if present, appear to have been added as temper. However, a few of the samples found on St Vincent were part of the Grenada petrographic group, containing (oxy)hornblende and zoned plagioclase, indicating a Grenada origin. They were therefore assumed to have been made on Grenada or from Grenada clay, and taken as evidence for interaction and exchange between the two islands.

A method was needed to compare the laboratory chemical data (from previous analyses) with the pXRF data for the same ceramic samples. The net peak area counts do not directly reflect the concentration of the elements in the samples (Wheeler 1999), and therefore cannot be directly compared to the chemical composition as determined by destructive analysis. Likewise, suitable matrix matched standards for whole ceramics do not exist, so attempts at quantifying the chemical composition from the pXRF data were impossible. Therefore, the ratios between elements were compared, as this provides a more robust reflection of the relationship between the elements. Matrix effects can increase and/or decrease the peak area counts for different elements, thereby changing the subsequent ratios. However, the destructive analysis of the ceramics indicated that the compositions within a specific island group are very similar and that these island groups are distinct from each other (Fig. 2). Therefore, it has been assumed that any enhancement or impairment of the peak fluorescence due to matrix effects would be similar for all the ceramics of a specific group. Similarly, the background varies across the spectrum and this also can affect the calculation of the correct peak area intensity. However, the ARTAX software 
The provenance of Cayo pottery from Grenada, Lesser Antilles

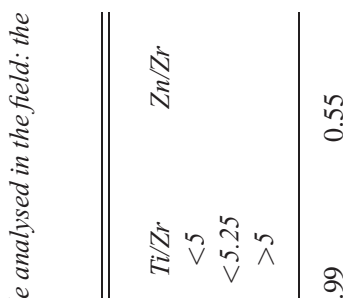

$\begin{array}{llllllll}7 & 0 & \infty & n & \ddots & + & 0 & \infty \\ 0 & 0 & 0 & 0 & 0 & 0 & 0 & 0 \\ +1 & +1 & +1 & +1 & +1 & +1 & +1 & +1\end{array}$

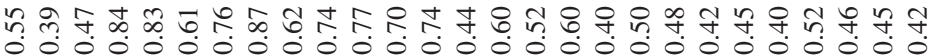

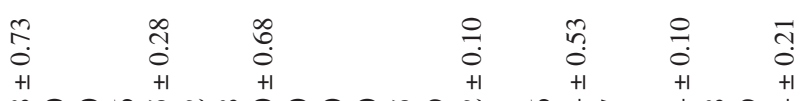
ma

\section{$\begin{array}{ccccc}-1 & 0 & 0 & 0 & 0 \\ 0 & 0 & 0 & 0 & 0 \\ +1 & +1 & +1 & +1 & +1\end{array}$}

के के का

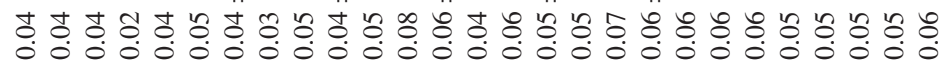

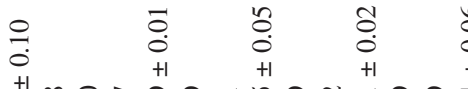

$\begin{array}{ccccc}0 & 0 & 0 & 0 \\ 0 & 0 & 0 & 0 \\ +1 & 0 & 0 & 0 \\ +1 & +1 & +1\end{array}$

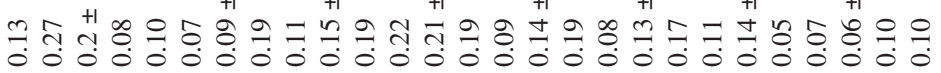
$\infty$
$\stackrel{\infty}{0}$
+1
$\hat{a}$

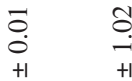

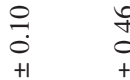
$\begin{array}{ll}2 & 0 \\ 0 & 0 \\ 0+1 & +1\end{array}$

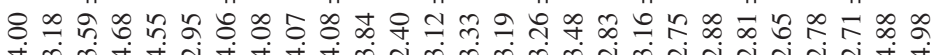

m तmmm min

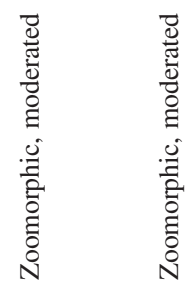

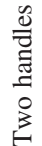

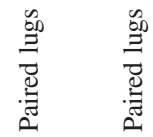

苛

હ

䒕 离

ஓ

胥

胥

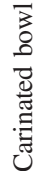

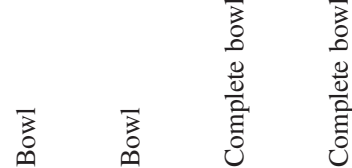

$\begin{array}{ll}\overline{3} & \overline{3} \\ 0 & 0 \\ 0 & 0\end{array}$ 


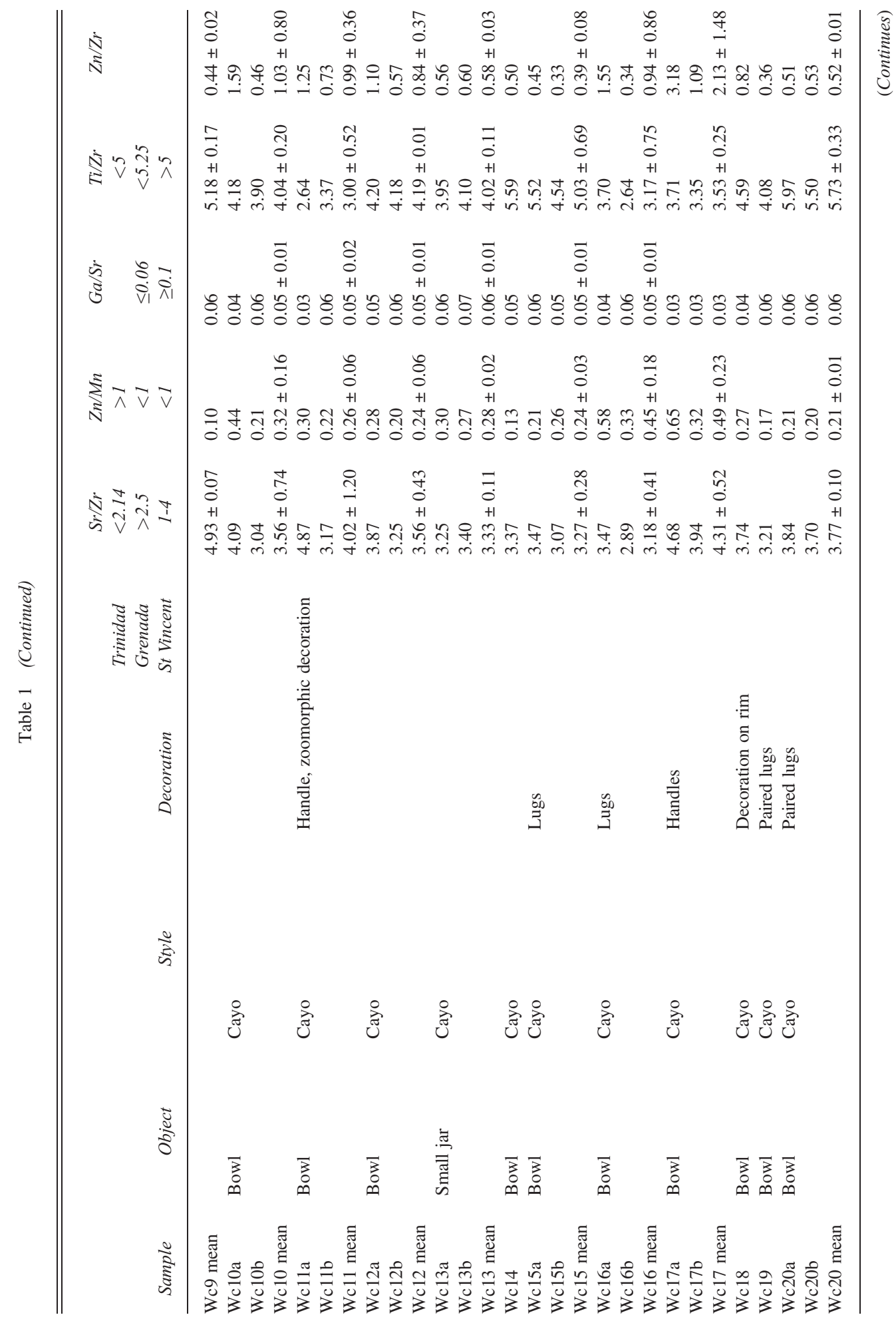


The provenance of Cayo pottery from Grenada, Lesser Antilles

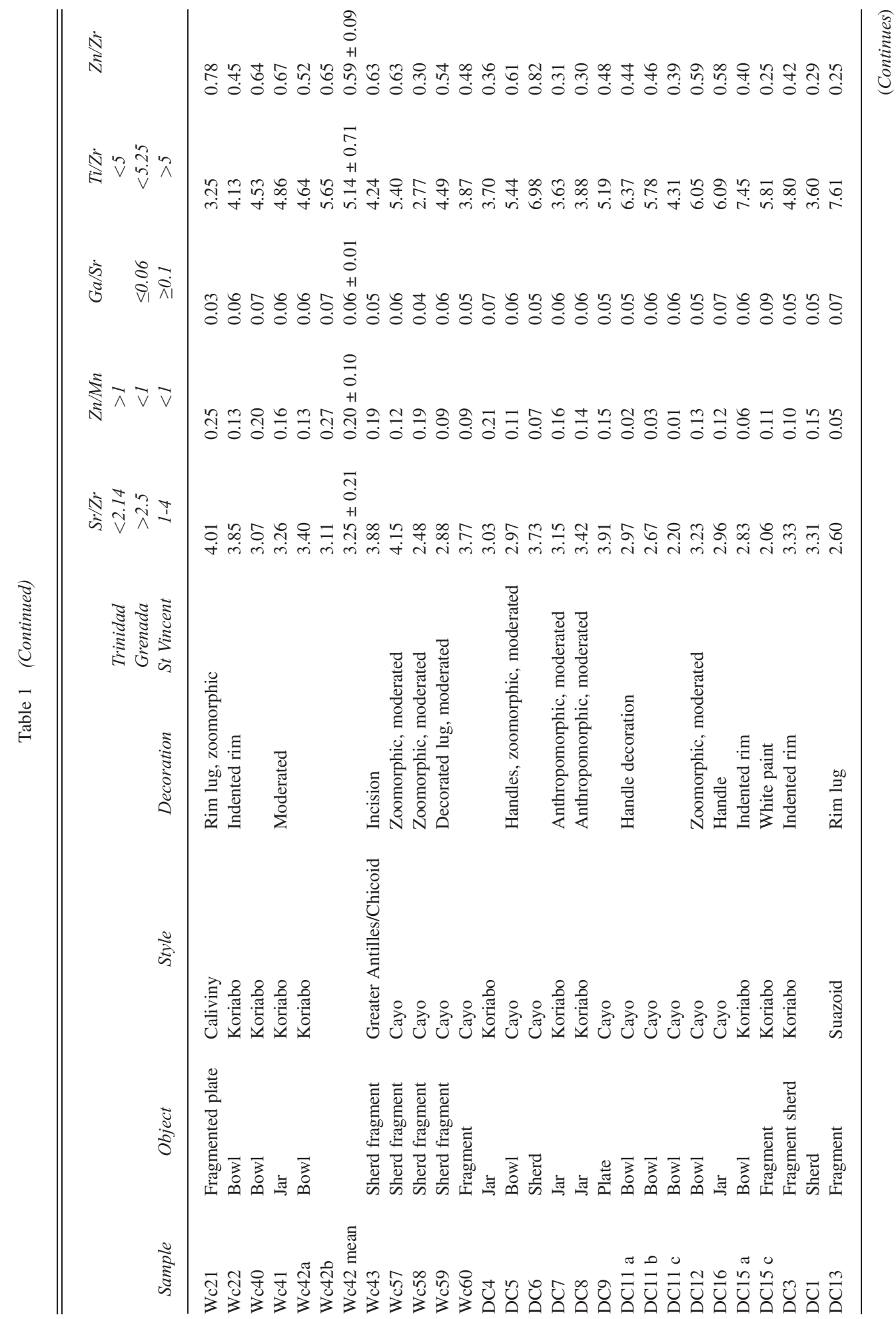

(c) 2018 University of Oxford, Archaeometry ••, •• (2018) ••-•• 
R. B. Scott et al.

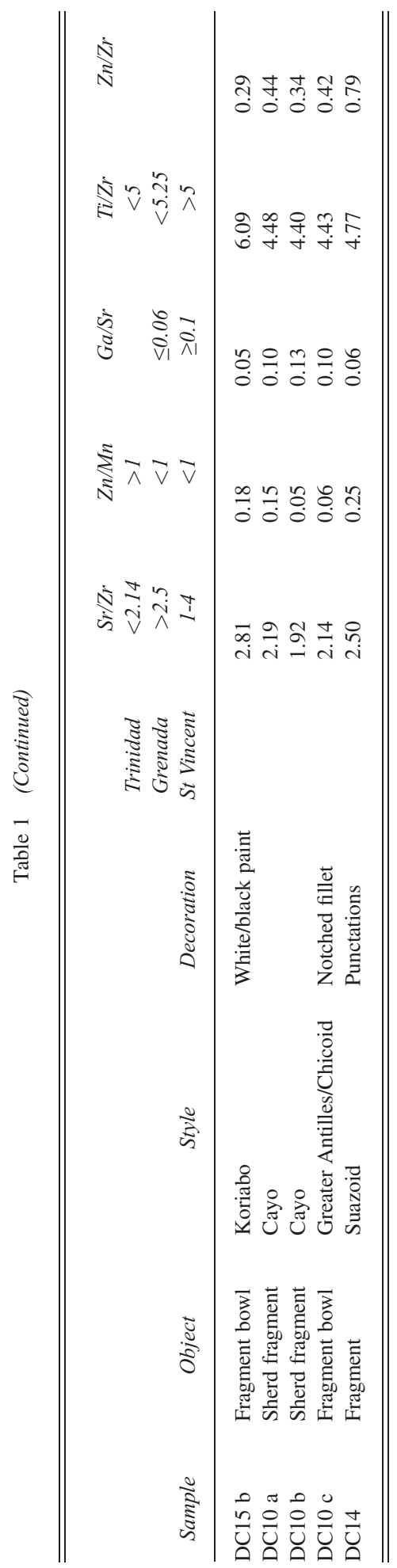



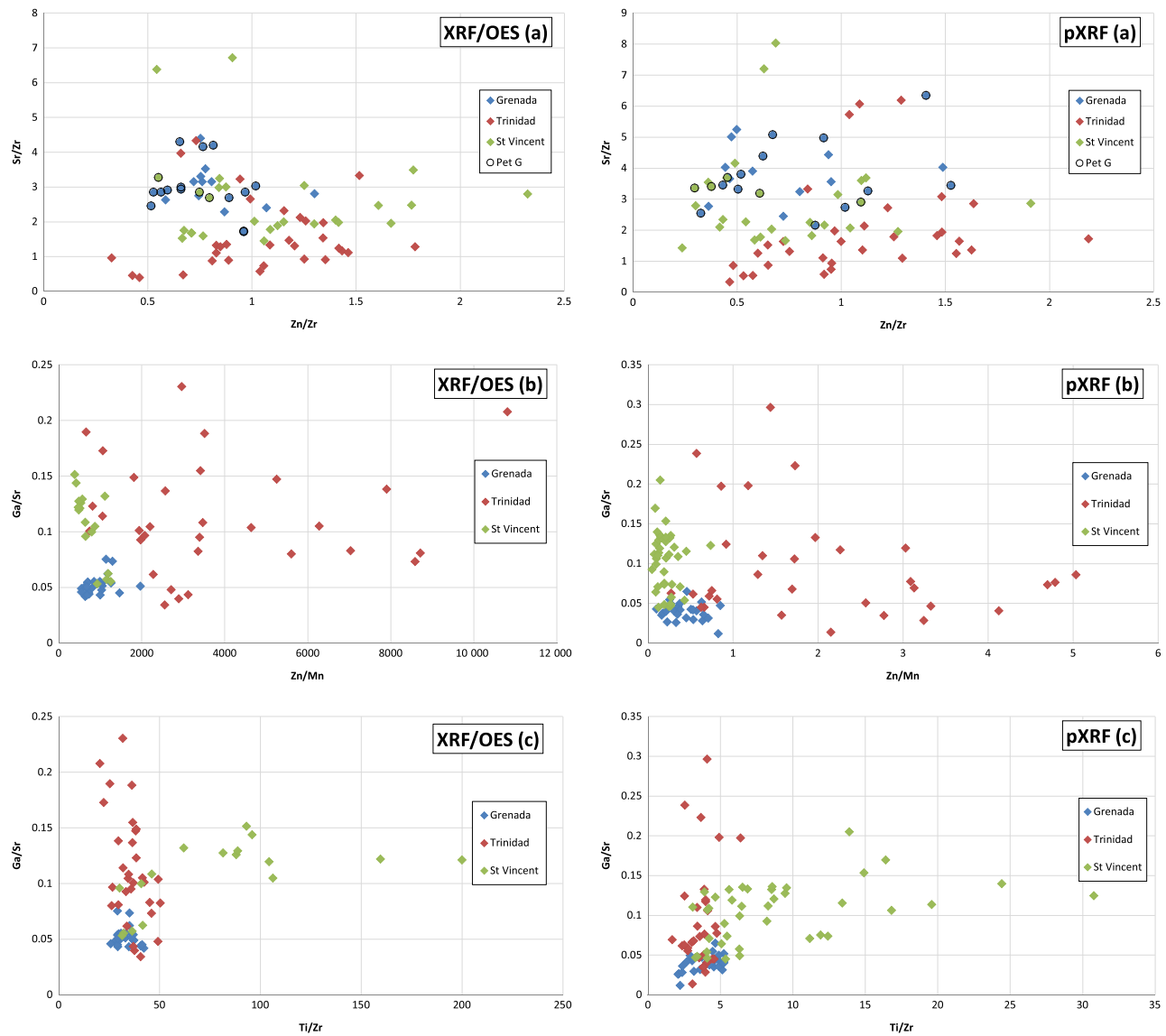

Figure 2 Biplots of the samples measured in the laboratory with (left-hand plots) destructive chemical analyses and (right-hand plots) pXRF to create the baseline data for different islands in the Lesser Antilles. The black open circles (a) indicate the samples that are petrographically part of the Grenada group. [Colour figure can be viewed at wileyonlinelibrary.com]

mathematically calculates the background for each individual peak when determining the net peak area intensity. Figure 2 (a) shows the ratios for $\mathrm{Zn} / \mathrm{Zr}$ against $\mathrm{Sr} / \mathrm{Zr}$ for the destructive laboratory chemical analysis (left-hand plot) and for the laboratory (L) pXRF (right-hand plot). This shows that while the (L) pXRF data is more dispersed than the chemical data, the same overall pattern is seen. Due to the dispersion in the $(\mathrm{L}) \mathrm{pXRF}$ data, there is a certain degree of overlap between the groups; however, by using a combination of ratios, the signature of the different islands can be determined (Fig. 2). Table 1 summarizes the (L) pXRF characteristics for the bulk of each island group. With the exception of seven samples (Fig. 2 (b), right), ceramics from Trinidad can be readily distinguished from the other islands, particularly in terms of $\mathrm{Sr} / \mathrm{Zr}(<2.14)$ and $\mathrm{Zn} / \mathrm{Mn}(>1)$. Some general observations can also made in terms of distinguishing St Vincent ceramic material from that of Grenada. Grenada ceramics tend to have a higher $\mathrm{Sr} / \mathrm{Zr}$ ratio (generally $>2.5$ ), the $\mathrm{Ga} / \mathrm{Sr}$ ratio is $\leq 0.06$ and the $\mathrm{Zn} / \mathrm{Mn}$ ratio is $<1$. These ceramics also have a fairly low $\mathrm{Ti} / \mathrm{Zr}$ ratio of $<5.25$. St Vincent ceramics have a noticeably higher $\mathrm{Ga} / \mathrm{Sr}$ ratio of $\geq 0.1$, and the $\mathrm{Ti} / \mathrm{Zr}$ ratio also tends to be $>5$. 
The overlap in the chemical signatures of the ceramic is most notable with the material from St Vincent and Grenada. Figure 2 (a) indicates the samples that belong to the Grenada petrographic group. The ceramics found on St Vincent that have the Grenada petrographic signature are also chemically similar to the material from Grenada in terms of both the laboratory chemical data and the (L) pXRF data. A principle components analysis (PCA) of the (L) pXRF data, using elements (Ti, Cr, Mn, Fe, Ni, Cu, Zn, Ga, Rb, Sr and Nb) ratioed over $\mathrm{Zr}$ and elements (Ti, Cr, Fe, Ni, Cu, $\mathrm{Zn}, \mathrm{Ga}, \mathrm{Rb}, \mathrm{Sr}, \mathrm{Zr}$ and $\mathrm{Nb}$ ) ratioed over $\mathrm{Mn}$ as the variables in a covariance matrix, indicated that a small overlap existed between the groups (Fig. 3 (a)). This again indicates that a small number of samples found amongst the St Vincent material plot with the Grenada material, including all the samples from the Grenada petrographic group. It was therefore decided that for comparative

(a)

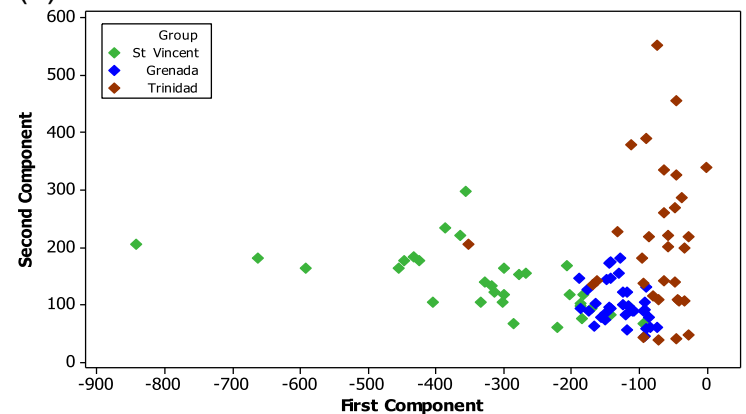

(b)

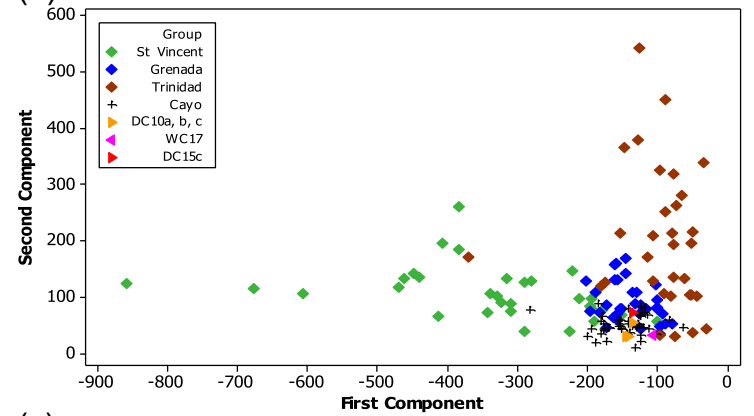

(c)

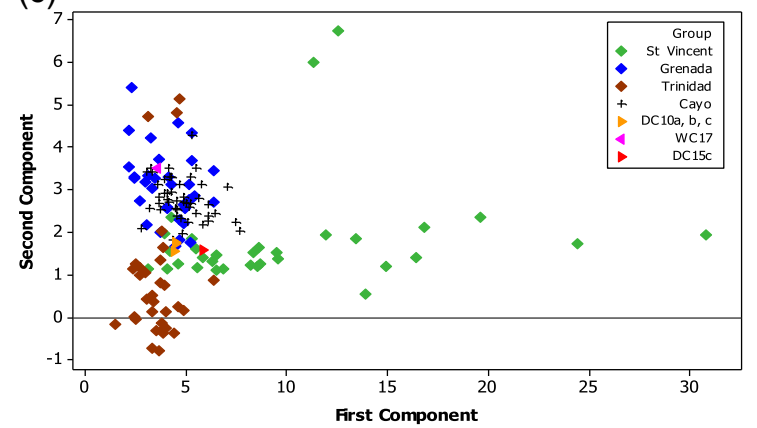

Figure 3 PCA plots of (a) the baseline laboratory data, (b) the Grenada Cayo samples (black crosses) in relation to the baseline data and (c) the Grenada Cayo samples in relation to the baseline data, but only using known diagnostic ratios as variables. [Colour figure can be viewed at wileyonlinelibrary.com] 
purposes with the field data, these samples would be treated as part of the Grenada group. While it is impossible to say for certain that all the St Vincent material that plots with Grenada, and the Grenada petrographic group, are from Grenada, it is highly likely that they share a common origin.

\section{Field analyses}

Fifty-two Cayo-style ceramic objects were analysed in the field (F) using pXRF (Table 1). The ceramics form one main group with $\mathrm{Sr} / \mathrm{Zr}=2.48-4.93, \mathrm{Zn} / \mathrm{Zr}=0.24-1.02, \mathrm{Ga} / \mathrm{Sr}=$ $0.02-0.07, \mathrm{Zn} / \mathrm{Mn}=0.01-0.48$ and $\mathrm{Ti} / \mathrm{Zr}=2.77-7.61$. The field data were plotted against the laboratory baseline data for the Lesser Antilles (Fig. 4). This clearly indicates that the majority of the samples plot within the spread of the Grenada laboratory data. Dispersion in pXRF data for ceramics is not unusual (Papachristodoulou et al. 2010; Gajić-Kvaščev et al. 2012; Ownby 2012); this is partly due to the use of different clay fractions (Papachristodoulou et al. 2010; Gajić-Kvaščev et al. 2012), but can also be related to post-depositional alteration processes (Papachristodoulou et al. 2010) and to sample heterogeneity. However, instrumental errors, such as counting statistics and X-ray tube stability, can also add to the scatter of the data (Krusberski 2006). In Figure 4 (a), the obvious outlier is Wc17: this sample had high $\mathrm{Zn}$, which contributes to the higher $\mathrm{Zn} / \mathrm{Zr}$ ratio (2.13). However, it should be remembered that the sample is heterogeneous and of an uneven shape. During the analysis of this particular ceramic, it was noted that large air gaps were present between the sample surface and the detector, and this will have influenced the fluorescence detection. Although some small air gaps were present during the analyses of many of the samples, in the case of Wc17 the gaps were noticeably larger. Figures 4 (b) and 4 (c) show that this sample groups with the rest of the Grenada data in terms of $\mathrm{Ga} / \mathrm{Sr}, \mathrm{Zn} / \mathrm{Mn}$ and $\mathrm{Ti} / \mathrm{Zr}$. Since the Grenada samples are all fairly dispersed in terms of the $\mathrm{Zn} / \mathrm{Zr}$ ratio, it is most likely that Wc17 is part of the Grenada group. The data for this sample should, however, be treated with caution. Five samples (DC11c, DC15c, DC10a, DC10b and DC10c; indicated by the red oval in Fig. 4 (a)), plot in the St Vincent region in terms of their $\mathrm{Sr} / \mathrm{Zr}$ ratios.

In order to investigate the extent to which samples DC11c, DC15c, DC10a, DC10b and DC10c are part of the Grenada group, the Ga/Sr ratios were plotted against $\mathrm{Zn} / \mathrm{Mn}$ (Fig. 4 (b)) and against $\mathrm{Ti} / \mathrm{Zr}$ (Fig. 4 (c)). Grenada ceramics typically have a $\mathrm{Ga} / \mathrm{Sr}$ ratio of $\leq 0.06$, while for St Vincent material this is typically $\geq 0.1$. Only three of the samples have $\mathrm{Ga} / \mathrm{Sr}$ ratios of $\geq 0.1$ (DC10a, DC10b and Dc10c, with 0.09, 0.10, 0.13 and 0.10, respectively); however, $\mathrm{DC} 15 \mathrm{c}$ has a relatively high $\mathrm{Ga} / \mathrm{Sr}$ ratio of 0.09 , which is noticeably higher than the bulk of the Grenada group. DC11c, on the other hand, has a $\mathrm{Ga} / \mathrm{Sr}$ ratio of 0.06 , putting it with the Grenada group. Although only $\mathrm{DC} 15 \mathrm{c}$ has a $\mathrm{Ti} / \mathrm{Zr}$ ratio $>5$, which is more indicative of a St Vincent origin, samples DC10a, DC10b and DC10c all plot with a small group of St Vincent/Trinidad mixed outliers (Fig. 4 (c)). Figure 4 (b) further clarifies this overlap between St Vincent and Trinidad, because $\mathrm{Zn}$ and $\mathrm{Mn}$ are good provenance indicators, as these tend to concentrate in the clay fraction and are highly immobile (Papachristodoulou et al. 2010; Gajić-Kvaščev et al. 2012). While the Zn/Mn contents of Grenada and St Vincent are fairly similar, they are noticeably different from those of Trinidad.

While it is clear from the biplots that the majority of the field samples belong to the Grenada compositional group, there are outliers and in some cases these appear to overlap 

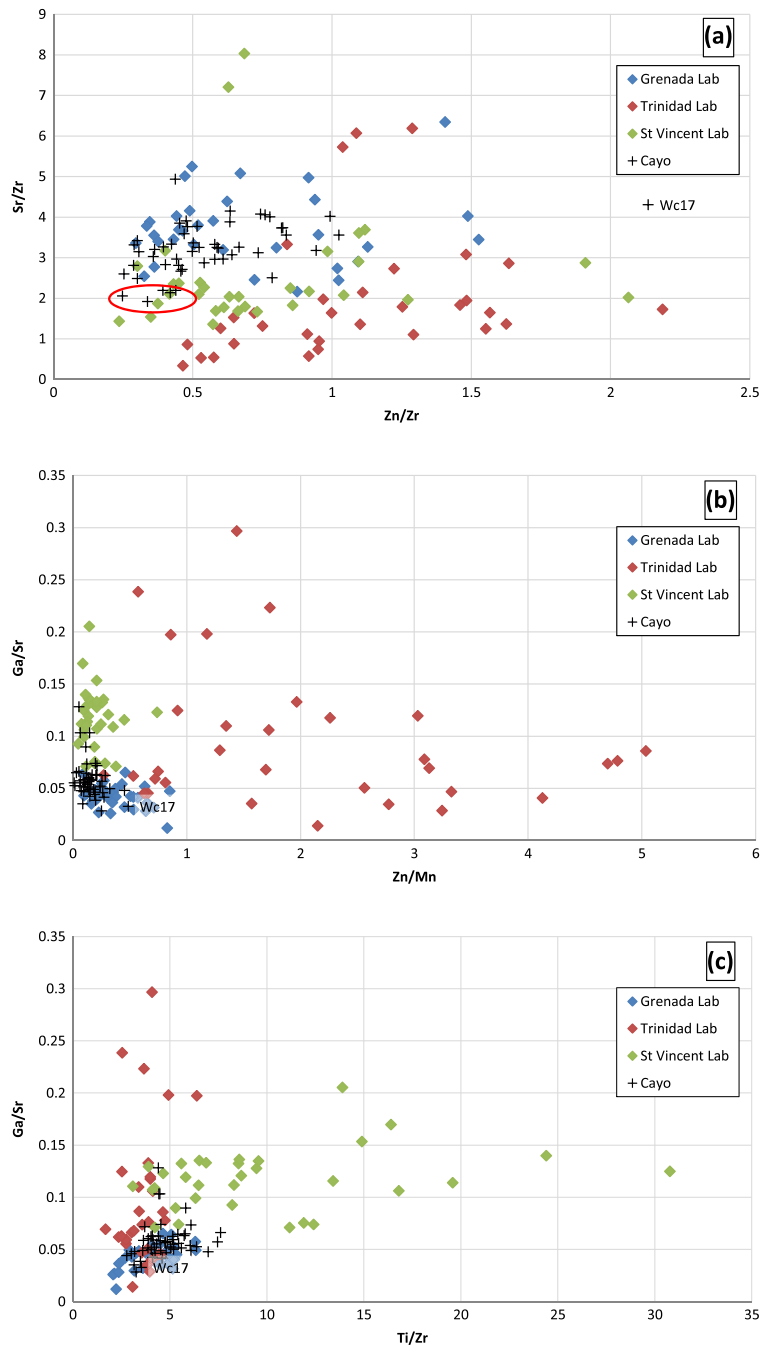

Figure 4 Biplots comparing the Grenada Cayo ceramics (black crosses) with the laboratory baseline data: the red ellipse in (a) indicates the four outliers that can be seen in plots (b) and (c). [Colour figure can be viewed at wileyonlinelibrary.com]

with material from either St Vincent or Trinidad. In order to try to resolve this overlap, a PCA was made with the field data, using the same variables as for the (L) pXRF data (Fig. 3 (b)). The biplots illustrate the basic geochemical relationships within the data, whereas PCA looks at the relative dispersion between the elemental ratios (Michelaki and Hancock 2011). The PCA shows all the samples clustering fairly tightly with the Grenada group; however, the overlap between the groups could not be completely eliminated. A further PCA plot (Fig. 3 (c)) was made using only the ratios that were known to distinguish between the groups (i.e., $\mathrm{Sr} / \mathrm{Zr}, \mathrm{Ti} / \mathrm{Zr}, \mathrm{Zn} / \mathrm{Zr}, \mathrm{Ga} / \mathrm{Sr}$ and $\mathrm{Zn} / \mathrm{Mn}$ ). Previous studies have noted that the use of non-diagnostic elements in a statistical analysis can obfuscate the compositional patterns seen in ceramic data (Forster et al. 2011; Michelaki and Hancock 2011). While this 
does further reduce the overlap between the Grenada and the St Vincent data, it still does not completely remove it. Figures 3 (b) and 3 (c) show that sample Wc17 is firmly within the Grenada group. However, statistically, samples DC15c, DC10a, DC10b and DC10c are similar to both the Grenada and the St Vincent material; therefore, they cannot be confidently assigned to either group. Were a petrographic analysis of these samples possible, then the issue would be fairly easily resolved.

\section{DISCUSSION}

The Caribbean is a relatively little studied area in terms of the compositional analyses of ceramic material (Bohus et al. 2005; Descantes et al. 2008; Hofman et al. 2008; Ting et al. 2016). Studies that do exist are mainly small-scale (Descantes et al. 2008), and are usually performed on a specific site or sites. Although attempts have been made to create a Caribbean database of ceramic chemical compositions (e.g., Descantes et al. 2008), the data that are available in the public domain are relatively sparse, and regional or interregional comparisons are rare. Since no matrix matched ceramic standards were available, a quantitative analysis with the pXRF was impossible to achieve. Therefore, in order to make the pXRF field data useful for wider studies, it was essential to create a method of relating the qualitative pXRF data to quantitative chemical and petrographic data. This was achieved by creating a baseline of (L) pXRF data from ceramic samples that had previously been analysed both with destructive chemical analysis and petrography.

The use of a pXRF to analyse ceramic material in the field relies on the user having a proper understanding of the material prior to analysis in order to ensure that the X-ray physics and resulting data give proper results (Shugar 2009). Likewise, it is essential to analyse matrix matched material in the laboratory prior to fieldwork in order to determine optimum operating parameters that are targeted to answering an appropriate research question (Scott et al. 2016b). The analysis of heterogeneous archaeological samples with pXRF requires users to be able to evaluate the accuracy, precision and sensitivity of the data (Speakman et al. 2011). It has been argued that as long as the precision of the instrument is high (Sheppard et al. 2011), and the researcher knows in advance which elements are reliable for discriminating between sources for a given study region (Nazaroff et al. 2010), then pXRF can be successfully used for provenancing studies (Scott et al. 2016a). In the case of this research, the (L) pXRF data of previously quantified samples was used to create a (L) pXRF baseline signature for part of the Lesser Antilles. This meant that the ceramics non-destructively analysed by (F) pXRF in Grenada could be compared to the data gathered in the laboratory to give an indication of the possible provenance. Since the baseline (L) pXRF data was created using ceramic samples that had a known chemical and petrographic signature, the baseline could be used as a proxy indication of the composition and likely petrography for pXRF data gathered in the field. Compositionally homogeneous groups are assumed to represent geographically restricted sources or source zones (Descantes et al. 2008). The analysis of the 52 Cayo ceramics from Grenada indicates that the majority of the samples form a single group with a few outliers.

Studies have indicated that the basalts of Grenada have abundant $\mathrm{Zr}$ contents associated with enriched $\mathrm{Sr}$ contents, and that the ratios of $\mathrm{Sr} / \mathrm{Zr}$ are systematically higher in material from Grenada compared to St Vincent (Devine 1995). To date, these high-Sr basalts have only been found in Grenada and the Grenadines (Stamper et al. 2014). This higher Sr/Zr ratio is also seen in the ceramics from Grenada, thus indicating a common provenance. Based 


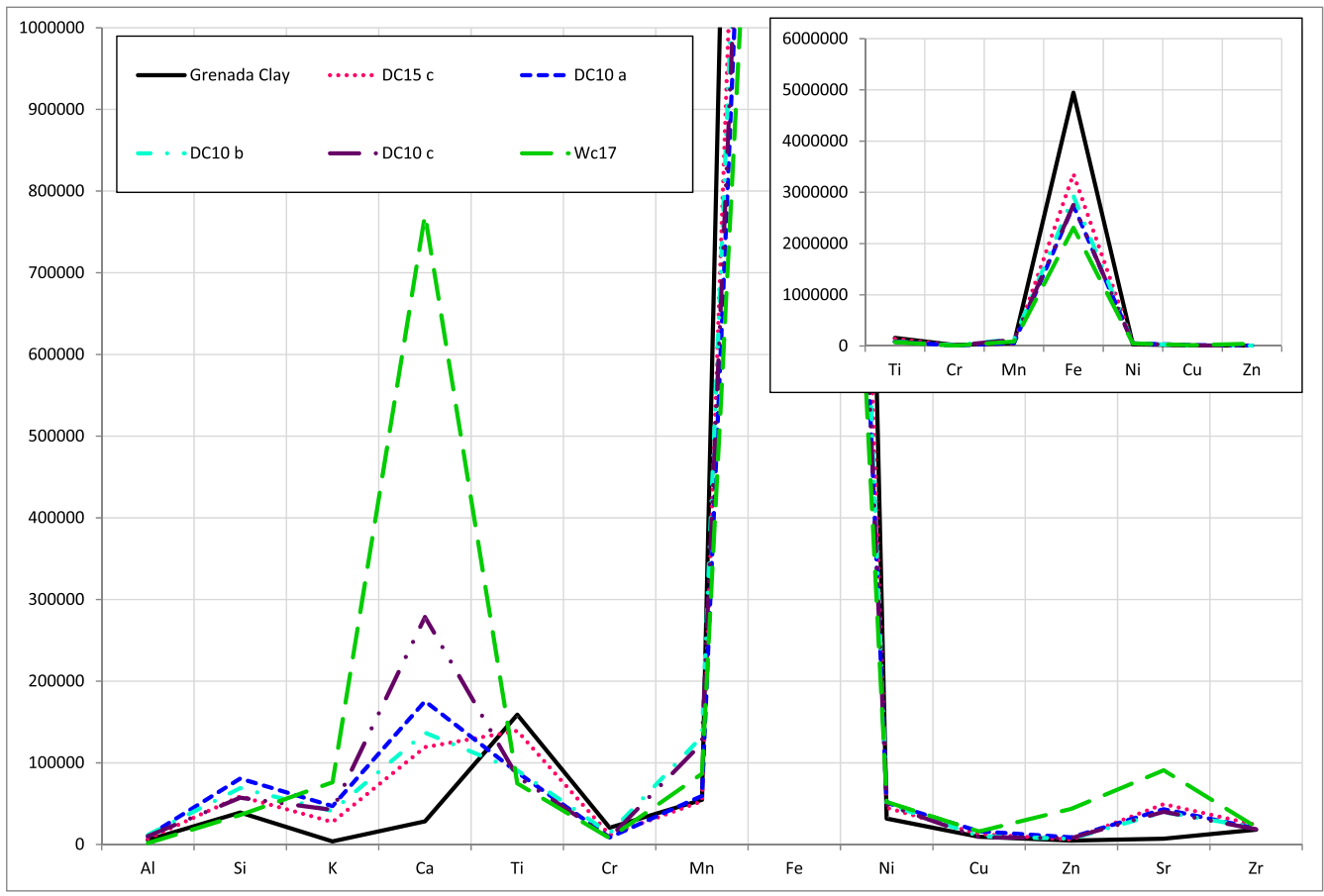

Figure 5 The solid (black) line is the Grenada fired clay sample, indicating high Ti, high Fe and low Ca. The dotted (pink) line is DC15c, the short dash (blue) line is DC10a, the dash-dot (turquoise) line is DC10b and the dash-dot-dot (purple) line is DC10c. The long dash (green) line is Wc17, which here represents the bulk of the Grenada ceramic group. [Colour figure can be viewed at wileyonlinelibrary.com]

on the geology of the wider area, it is probable that the majority of the ceramics found on Grenada were either made in Grenada (or the Grenadines), due to the high $\mathrm{Sr} / \mathrm{Zr}$ ratios and the low $\mathrm{Zn} / \mathrm{Mn}$ ratios.

As a pilot study, a lateritic red clay was sampled from Grenada and a fired sample was analysed using the (L) pXRF. The resulting spectrum was compared with the spectra of ceramics analysed by (F) pXRF on Grenada (Fig. 5). The clay from Grenada has low Ca, high $\mathrm{Ti}$ and high $\mathrm{Fe}$, and is a possible source of the clay used for the ceramics analysed in the field. Although the ceramics have higher Ca contents than the Grenada clay sample, this element can be added during the manufacturing process. Nevertheless, without an analysis of all the possible workable clay sources on Grenada, it is impossible to prove a local clay raw material origin.

\section{Archaeological implications}

The existence of workable clay sources for pottery production on Grenada is evidenced by the remains of kilns and pottery production sites dating to the colonial period. It is therefore not surprising to find that Cayo ceramics found on Grenada would have been made with clay local to the island. The preliminary laboratory analysis indicated that a few of the samples used to create the baseline data, which were found on St Vincent, were produced with clay from Grenada. This gives a clear indication that either raw material or finished pots moved or were 
exchanged from Grenada to St Vincent. However, so far, we have no direct evidence to suggest ceramic exchange in the opposite direction. Four of the 52 samples measured on Grenada may potentially originate from another island.

While, stylistically, some of the Grenada ceramics appear similar to the Koriabo complex from the mainland, they appear to be made from clay local to the area, suggesting a local production of Koriabo-affiliated pottery. This implies that, in this instance, people and ideas were moving from the mainland to the islands rather than the objects themselves. Due to the abundant raw clay material on Grenada, the exchange of indigenous Caribbean ceramics from other islands would have been unnecessary. It has been argued in other places in the Caribbean that the spread of a pottery style over a variety of islands could be indicative of peaceful interactions (Rouse 1992; Keegan 2006). The composition of the Cayo ceramics from Grenada arguably supports this hypothesis, since the typology is similar between the islands but local raw materials were used. In order to maintain social ties between the island and mainland communities, exchange relationships were probably pivotal (Hofman et al. 2007). Other objects found at La Poterie and Telescope Point, including pendants made of peccary and tapir teeth, and flutes made of deer bone (Lafoon in Hofman 2016), indicate clear contact with the mainland, reflecting the maintenance of such ties.

\section{CONCLUSION}

In order to successfully analyse and possibly provenance Cayo ceramic with (F) pXRF in the Caribbean, a baseline linking the (L) pXRF signal to that of the quantified chemical and petrographic signature of the different islands needed to be created. The subsequent $(\mathrm{F}) \mathrm{pXRF}$ analysis of Cayo ceramics on Grenada indicated that the majority of the field data could be assigned to the Grenada chemical and petrographic group, with this island being the probable source of the clay raw material. However, four samples (DC15c, DC10a, DC10b and DC10c) could not be definitively assigned to the 'local' ceramic compositional group.

Further targeted study of the different clay sources on the various islands of the Lesser Antilles would be necessary to improve the provenance determination. However, the similarity in geology between the islands and the increased dispersion in the pXRF data means that a destructive chemical analysis of these potential sources would be needed. Even with further work, overlap in the pXRF data may not be fully resolved. While ceramics with distinctly different pXRF element ratios can be confidently assigned to a particular island, samples that fall within the overlap zones may only be assigned to a regional source. The use of a baseline, created from quantified chemical and petrographic data, is essential in such a study. Studies comparing the (L) pXRF signal measured on the external surface of the ceramic with the quantified chemical data ensured that the patterns seen in the $\mathrm{pXRF}$ data were valid and not an artefact due to matrix effects. The preliminary work also indicated that, in this instance, the pXRF distinction between the groups was robust enough to merit taking and using the instrument in the field.

\section{ACKNOWLEDGMENTS}

The results presented here are an outcome of the CARIB project 'Caribbean connections: cultural encounters in a New World setting', financed by the Humanities in the European Research Area (HERA grant number 1133). This is a collaboration between Leiden University, KU Leuven, the University of Konstanz, Caribbean GOs, NGOs and community members. We would like to acknowledge Mr Dolton Charles and the Willcox family from Grenada for giving us access to 
their collections for the purpose of this study. We would also like to acknowledge the Grenada Ministry of Culture, the La Poterie community and Cleopatrice Andrews for the permissions granted to excavate the site of La Poterie. In addition, we would like the thank the anonymous referees for their comments and improvements to the manuscript.

\section{REFERENCES}

Bohus, L. S., Mackowiak de Antczak, M. M., Greaves, E. D., Antczak, A., Bermudez, J., Kasztovszky, Z., Poirier, T., and Simonits, A., 2005, Incipient archaeometry in Venexuela: provenance study of pre-Hispanic pottery figurines, Journal of Radioanalytical and Nuclear Chemistry, 265(2), 247-56.

Boomert, A., 1986, The Cayo complex of St. Vincent: ethnohistorical and archaeological aspects of the Island Carib problem, Anthropologica, 66, 3-68.

Boomert, A., 2004, Koriabo and the polychrome tradition: the late-prehistoric era between the Orinoco and the Amazon mouths, in Late ceramic age societies in the eastern Caribbean (eds. A. Delpuech and C. L. Hofman), 251-66, Archaeopress, Oxford.

Boomert, A., 2011, From Cayo to Kalinago: aspects of Island Carib archaeology, in Communities in contact (eds. C. Hofman and A. van Duijvenbode), 291-306, Sidestone Press, Leiden.

Bright, A. J., 2011, Blood is thicker than water, Sidestone Press, Leiden.

Carter, T., and Shackley, M. S., 2007, Sourcing obsidian from Neolithic Çatalhöyük (Turkey) using energy dispersive X-ray fluorescence, Archaeometry, 49, 437-54.

Craig, N., Speakman, R. J., Popelka-Filcoff, R. S., Glascock, M. D., Robertson, J. D., Shackley, M. S., and Aldenderfer, M. S., 2007, Comparison of XRF and pXRF for analysis of archaeological obsidian from southern Peru, Journal of Archaeological Science, 34, 2012-24.

Degryse, P., and Braekmans, D., 2014, Elemental and isotopic analysis of ancient ceramics and glass, in Treatise on geochemistry (eds. H. D. Holland and K. K. Turekian), 191-207, 2nd edn, Elsevier, Oxford.

Descantes, C., Speakman, R. J., and Glascock, M. D., 2008, Compositional studies of Caribbean ceramics: an introduction to instrumental neutron activation analysis, Journal of Caribbean Archaeology, Special Publication, $1-4$.

Devine, J. D., 1995, Petrogenesis of the basalt-andesite-dacite association of Grenada, Lesser Antilles island arc, revisited, Journal of Volcanology and Geothermal Research, 69, 1-33.

Forster, N., Grave, P., Vickery, N., and Kealhofer, L., 2011, Non-destructive analysis using PXRF: methodology and application to archaeological ceramics, X-Ray Spectrometry, 40, 389-98.

Franklin, U. M., and Vitali, V., 1985, The environmental stability of ancient ceramics, Archaeometry, 27, 3-15.

Freestone, I. C., 2001, Post-depositional changes in archaeological ceramics and glasses, in Handbook of archaeological sciences (eds. D. R. Brothwell and A. M. Pollard), 615-25, Wiley, Chichester.

Gajić-Kvaščev, M. D., Marić-Stojanović, M. D., Jančić-Heinemann, R. M., Kvaščev, G. S., and Andrić, V. D., 2012, Non-destructive characterisation and classification of ceramic artefacts using pEDXRF and statistical pattern recognition, Chemistry Central, 6(102), 1-9.

Goodale, N., Bailey, D. G., Jones, G. T., Prescott, C., Scholz, E., Stagliano, N., and Lewis, C., 2012, pXRF: a study of inter-instrument performance, Journal of Archaeological Science, 39, 875-83.

Goren, Y., Mommsen, H., and Klinger, J., 2011, Non-destructive provenance study of cuneiform tablets using portable X-ray fluorescence (pXRF), Journal of Archaeological Science, 38, 684-96.

Helmig, D., Jackwerth, E., and Hauptmann, A., 1989, Archaeometallurgical fieldwork and the use of a portable X-ray spectrometer, Archaeometry, 31, 181-91.

Hofman, C. L., 2013, The post Saladoid in the Lesser Antilles, in Oxford handbook of Caribbean archaeology (eds. W. F. Keegan, C. L. Hofman, and R. Rodriguez Ramos), 205-20, Oxford University Press, Oxford.

Hofman, C. L., 2016, Fieldwork report Grenada, Leiden.

Hofman, C. L., and Bright, A. J., 2010, Towards a pan-Caribbean perspective of the pre-Colonial mobility and exchange: preface to a special volume of the Journal of Caribbean Archaeology, Journal of Caribbean Archaeology, 3,1 .

Hofman, C. L., and Hoogland, M. L. P., 2012, Caribbean encounters: rescue excavations at the early colonial Island Carib site of Argyle, St. Vincent, Analecta Praehistorica Leidensia, 63-76.

Hofman, C. L., Hoogland, M. L. P., and Roux, B., 2015, Reconstruire le táboüi, le manna et les pratiques funéraires au village caraïbe d'Argyle, Saint-Vincent, in À la recherche du Carä̈be perdu: Les populations amérindiennes des Petites Antilles de l'époque précolombienne à la période coloniale (ed. B. Grunberg), 41-50, L'Harmattan, Paris. 
Hofman, C. L., Hoogland, M. L. P., and van Gijn, A. L. (eds.), 2008, Crossing the borders: new methods and techniques in the study of archaeological materials from the Caribbean, University of Alabama Press, Tuscaloosa, AL.

Hofman, C. L., Bright, A. J., Boomert, A., and Knippenberg, S., 2007, Island rhythms: the web of social relationships and interaction networks in the pre-Columbian Lesser Antilles, Latin American Antiquity, 18(3), 243-68.

Hofman, C. L., Mol, A. A. A., Hoogland, M. L. P., and Valcárcel Rojas, R., 2014, Stage of encounters: migration, mobility and interaction in the pre-colonial and early colonial Caribbean, World Archaeology, 46(4), 590-609.

Hoogland, M. L. P., Hofman, C. L., and Boomert, A., 2011, Argyle, St Vincent: new insights on the Island Carib occupation of the Lesser Antilles, in 24th International Congress for Caribbean Archaeology, Martinique.

Hunt, A. M. W., and Speakman, R. J., 2015, Portable XRF analysis of archaeological sediments and ceramics, Journal of Archaeological Science, 53, 1-3.

Johnson, J., 2014, Accurate measurements of low $Z$ elements in sediments and archaeological ceramics using portable X-ray fluorescence (PXRF), Journal of Archaeological Method and Theory, 21, 563-88.

Keegan, W. F., 2006, Archaic influences in the origins and development of Taino societies, Caribbean Journal of Science, 42(1), 1-0.

Krusberski, N., 2006, Exploring potential errors in XRF analysis, in Analytical challenges in metallurgy, 1-8, The Southern African Institute of Mining and Metallurgy, Johannesburg.

Lundblad, S. P., Mills, P. R., and Hon, K., 2008, Analysing archaeological basalt using non-destructive energy-dispersive X-ray fluorescence (EDXRF): effects of post-depositional chemical weathering and sample size on analytical precision, Archaeometry, 50, 1-1.

Mantler, M., and Schreiner, M., 2000, X-ray fluorescence spectrometry in art and archaeology, X-Ray Spectrometry, 29, $3-17$.

Michelaki, K., and Hancock, R. G. V., 2011, Chemistry versus data dispersion: is there a better way to assess and interpret archaeometric data? Archaeometry, 53, 1259-79.

Morgenstein, M., and Redmount, C. A., 2005, Using portable energy dispersive X-ray fluorescence (EDXRF) analysis for on-site study of ceramic sherds at El Hibeh, Egypt, Journal of Archaeological Science, 32, 1613-23.

Nazaroff, A. J., Prufer, K. M., and Drake, B. L., 2010, Assessing the applicability of portable X-ray fluorescence spectrometry for obsidian provenance research in the Maya lowlands, Journal of Archaeological Science, 37, 885-95.

Ownby, M. F., 2012, The use of portable X-ray fluorescence spectrometry for analyzing ancient ceramics, Archaeology Southwest Magazine, 26(2), 1-5.

Papachristodoulou, C., Gravani, K., Oikonomou, A., and Ioannides, K., 2010, On the provenance and manufacture of red-slipped fine ware from ancient Cassope (NW Greece): evidence by X-ray analytical methods, Journal of Archaeological Science, 37, 2146-54.

Petitjean Roget, H., 2015, Les Tainos, les Callinas des Antilles, IACA, Basse-Terre.

Potts, P. J., Webb, P. C., and Williams-Thorpe, O., 1997, Investigation of a correction procedure for surface irregularity effects based on scatter peak intensities in the field analysis of geological and archaeological rock samples by portable X-ray fluorescence spectrometry, Journal of Analytical Atomic Spectrometry, 12, 769-76.

Rouse, I., 1992, The Tainos: rise and decline of the people who greeted Columbus, Yale University Press, New Haven, CT.

Schreiner, M., Frühmann, B., Jembrih-Simbürger, D., and Linke, R., 2004, X-rays in art and archaeology-an overview, Advances in X-Ray Analysis, 47, 1-7.

Scott, R. B., Eekelers, K., and Degryse, P., 2016a, Quantitative chemical analysis of archaeological slag material using handheld X-ray fluorescence spectrometry, Applied Spectroscopy, 70(1), 94-109.

Scott, R. B., Eekelers, K., Fredericks, L., and Degryse, P., 2016b, A methodology for qualitative archaeometallurgical fieldwork using a handheld X-ray fluorescence spectrometer, STAR: Science and Technology of Archaeological Research, 1(2), 70-80.

Shackley, M. S., 2011, X-ray fluorescence spectrometry in twenty-first century archaeology, in X-ray fluorescence spectrometry $(X R F)$ in geoarchaeology (ed. M. S. Shackley), 1-6, Springer, New York.

Sheppard, P. J., Irwin, G. J., Lin, S. C., and McCaffrey, C. P., 2011, Characterisation of New Zealand obsidian using pXRF, Journal of Archaeological Science, 38, 45-56.

Shugar, A., 2009, Peaking your interest: an introductory explanation of how to interpret XRF data, WAAC Newsletter, 31(3), 8-10.

Shugar, A. N., and Mass, J. L., 2012, Introduction, in Handheld XRF for art and archaeology (eds. A. N. Shugar and J. L. Mass), 17-36, Leuven University Press, Leuven. 
Speakman, R. J., Little, N. C., Creel, D., Miller, M. R., and Iñañez, J. G., 2011, Sourcing ceramics with portable XRF spectrometers? A comparison with INAA using Mimbres pottery from the American Southwest, Journal of Archaeological Science, 38, 3483-96.

Stamper, C. C., Blundy, J. D., Arculus, R. J., and Melekhova, E., 2014, Petrology of plutonic xenoliths and volcanic rocks from Grenada, Lesser Antilles, Journal of Petrology, 55(7), 1353-87.

Ting, C., Neyt, B., Ulloa Hung, J., Hofman, C., and Degryse, P., 2016, The production of pre-Colonial ceramics in northwestern Hispaniola: a technological study of Meillacoid and Chicoid ceramics from La Luperona and El Flaco, Dominican Republic, Journal of Archaeological Science: Reports, 6, 376-85.

Tite, M. S., 2008, Ceramic production, provenance and use-a review, Archaeometry, 50(2), 216-31.

Wheeler, B. D., 1999, Analysis of limestones and dolomites by X-ray fluorescence, The Rigaku Journal, 16(1), 16-25.

Wisseman, S. U., Emerson, T. E., Hynes, M. R., and Hughes, R. E., 2004, Using a portable spectrometer to source archaeological materials and to detect restorations in museum objects, Journal of the American Institute for Conservation, 43(2), 129-38. 